\title{
Notes from the Editor
}

For more than a century and a half, Democracy in America has been an indispensable starting point for understanding American politics. After the second volume of Democracy was published in 1840, Tocqueville continued to monitor political developments in this country and committed many of his thoughts to paper, in letters to friends in America. Unfortunately, his epistolary ruminations have never been translated into English, and their very existence seems to have largely been ignored until now. In "The Third Democracy: Tocqueville's Views of America after 1840," Aurelian Craiutu and Jeremy Jennings use the post-1840 letters to tell the rest of the story-or, as they put it, to "reconstruct what Volume Three of Democracy might have looked like if it had ever been written." (The portrayal of party canvassing on the cover of this issue commemorates that period in American politics.) Craiutu and Jennings's creative reconstruction reveals a significant change in Tocqueville's perspective, and more specifically a growing disenchantment with America occasioned by his sense that such problems as corruption, slavery, imperialism, and the encroachment of the economic sphere upon the political would jeopardize freedom and stability in America. Thus, rather than the relatively sunny picture that emerged from the first two volumes of Democracy, Craiutu and Jennings argue that the excesses of democracy in America would have been the central focus of the final volume of Tocqueville's seminal work.

In "Madison vs. Hamilton: The Battle Over Republicanism," Colleen Sheehan takes another fresh look at the early period of the American republic, this time to shed light on a feud that "left a lasting impression on the American political landscape." Sheehan's focus is on the philosophical differences that led Alexander Hamilton and James Madison, erstwhile allies in coauthoring the Federalist Papers, to become politically estranged during the 1790s. Their dispute was not one of personal animosity or, as is often claimed, the result of Madison giving in to his affection for Thomas Jefferson. Rather, Sheehan argues that the conflict between Hamilton and Madison was propelled by their fundamental disagreement over the nature and role of public opinion in a republican government-an issue that has been played out, in America and elsewhere, over the succeeding two centuries.

Echoes of that conflict can be heard in David J. Samuels's "Presidentialism and Accountability for the Economy in Comparative Perspective." Democratic principles require that public officials be accountable to the voters for their actions. This is most easily realized when voters are able to attribute policy success and failures to specific political decision makers. Samuels's contribution is to investigate the impact of institutional, electoral, and political rules and forces on accountability in 23 presidential democracies. Although the virtues and vices of presidential and parliamentary systems are often disputed, Samuels finds that accountability is achievable in either type of system. The crucial factor, he concludes, is not a presidential versus a parliamentary structure as such, but rather the concurrence or non-concurrence of elections; in short, the timing is what matters-a new perspective on a long-running debate.

In many newly industrializing states, the key to success is often seen as the liberalization of the state-led economy. In most, if not all, instances, liberalization has been based on an invariant set of assumptions about how individuals make economic choices. However, a body of cultural and psychological research indicates that people in different societies make choices according to different criteria. In "It's Not Whether You Win or Lose, But How You Play the Game: Self-Interest, Social Justice, and Mass Attitudes toward Market Transition," Raymond M. Duch and Harvey D. Palmer use a combination of survey and experimental data collected in the West African nation of Benin to address the micro-foundations of market-based solutions to economic transition and development. Benin provides an ideal research locale for their purposes, Duch and Palmer argue, because the behavioral assumptions of classical micro-economics are least likely to hold in such a setting. It is thus striking that Duch and Palmer find that, although there are indeed variations in Benin in the way that "social capital" is employed, these differences do not extend to basic economic reasoning. This evidence, drawn from a most-likely case for the importance of cultural differences, offers a more nuanced view of economic decision making and in doing so suggests ways that tailoring incentive programs to local social conditions could enhance their effectiveness and economic growth.

In "Credible Commitment and Property Rights: Evidence from Russia," Timothy M. Frye also delves in the micro-foundations of economic growth. Drawing on surveys of company managers in Russia, Frye considers the ideas that property rights are threatened by private agents and secured by state institutions or, alternatively, attenuated by the arbitrary exercise of state power. Frye's results suggest the need to reconsider such sharply contrasting perspectives, for the pattern that emerges is more subtly nuanced and has wideranging implication for policy reform in the Russian case and, by extension, elsewhere as well.

From government regulation in Russia, this issue executes a half-turn to consider government regulation in the United States. Scholars of bureaucratic and legislative politics have long wrestled with the challenge of how to test theoretical models asserting congressional influence. Charles R. Shipan, in "Regulatory Regimes, Agency Actions, and the Conditional Nature of Congressional Influence," rises to the challenge and in so doing provides intriguing evidence that the real question is not whether Congress can regulate its bureaucratic agents, but rather when it is best positioned to do so. Shipan presents a model that integrates 
the role of both the executive and legislative branches, particularly the congressional committee system, to constrain bureaucratic actors and, in an especially nice example of the complementarity of formal and empirical approaches, tests that model against the monitoring activities of the Food and Drug Administration.

When bureaucrats are too smart or too capable for their principals' good, the would-be principals face a dilemma that has served as a source of much theoretical and empirical work. But what if the opposite were true? That is, what would happen if bureaucrats were unable to do what was expected of them? In "Bureaucratic Capacity, Delegation, and Political Reform," John Huber and Nolan McCarty show that when agents are unable to fulfill their assigned tasks, the effects are not simple or straightforward. Their exposition promises to open up a whole new discussion on why agents will not-or cannot-fulfill their principals' goals.

Another modeling exercise was inspired by the "doctrinal paradox" of law and economics, in which majority concurrence on decision premises does not necessarily produce majority concurrence on a resolution. Christian List's "Model of Path-Dependence in Decisions over Multiple Propositions" focuses on pathdependent decisions. For a system of law and policy to remain coherent, future rulings, amendments, and the like must accept earlier decisions as necessary foundations. In essence, the order in which propositions are considered may affect a decision's outcome. This type of constraint occurs when individuals are boundedly rational and when decisions are collective. Such pathdependence allows strategic agenda-setters to manipulate outcomes by altering the order in which propositions are considered. More subtly, the existence of alternative decision-paths provides a rationale for actors to lie about the virtues of alternatives.

Finally, the concluding article in this issue steps away from the abstract and highly formalized approach represented in the Huber-McCarty and List analyses to consider some concrete and very familiar manifestations of American politics. Are "soccer moms" and "NASCAR dads" real and significant groups in the American political landscape? Or are they journalistic hyperboles? According to Janet Box-Steffensmeier, Suzanna De Boef, and Tse-min Lin in "The Dynamics of the Partisan Gender Gap", there are indeed enduring and important differences in the ways American men and women think and vote. By analyzing survey data over a two-decade span, these authors show that underlying demographic and cultural changes in the populace have made the differences between the genders as pervasive as those between "red states" and "blue states."

\section{INSTRUCTIONS TO CONTRIBUTORS}

\section{General Considerations}

The APSR strives to publish scholarly research of exceptional merit, focusing on important issues and demonstrating the highest standards of excellence in conceptualization, exposition, methodology, and craftsmanship. Because the APSR reaches a diverse audience of scholars and practitioners, authors must demonstrate how their analysis illuminates a significant research problem, or answers an important research question, of general interest in political science. For the same reason, authors must strive for a presentation that will be understandable to as many scholars as possible, consistent with the nature of their material.

The APSR publishes original work. Therefore, authors should not submit articles containing tables, figures, or substantial amounts of text that have already been published or are forthcoming in other places, or that have been included in other manuscripts submitted for review to book publishers or periodicals (including on-line journals). In many such cases, subsequent publication of this material would violate the copyright of the other publisher. The APSR also does not consider papers that are currently under review by other journals or duplicate or overlap with parts of larger manuscripts that have been submitted to other publishers (including publishers of both books and periodicals). Submission of manuscripts substantially similar to those submitted or published elsewhere, or as part of a book or other larger work, is also strongly discouraged. If you have any questions about whether these policies apply in your particular case, you should discuss any such publications related to a submission in a cover letter to the Editor. You should also notify the Editor of any related submissions to other publishers, whether for book or periodical publication, that occur while a manuscript is under review by the APSR and which would fall within the scope of this policy. The Editor may request copies of related publications.

If your manuscript contains quantitative evidence and analysis, you should describe your procedures in sufficient detail to permit reviewers to understand and evaluate what has been done and, in the event that the article is accepted for publication, to permit other scholars to carry out similar analyses on other data sets. For example, for surveys, at the least, sampling procedures, response rates, and question wordings should be given; you should calculate response rates according to one of the standard formulas given by the American Association for Public Opinion Research, Standard Definitions: Final Dispositions of Case Codes and Outcome Rates for Surveys (Ann Arbor, MI: AAPOR, 2000). This document is available on the Internet at <http:/www.aapor.org /default.asp? page = survey_methods/standards_and_ best_practices/standard_definitions $>$. For experiments, provide full descriptions of experimental protocols, methods of subject recruitment and selection, subject payments and debriefing procedures, and so on. Articles should be self-contained, so you should not simply refer readers to other publications for descriptions of these basic research procedures.

Please indicate variables included in statistical analyses by capitalizing the first letter in the variable name and italicizing the entire variable name the first time each is mentioned in the text. You should also use 
the same names for variables in text and tables and, wherever possible, should avoid the use of acronyms and computer abbreviations when discussing variables in the text. All variables appearing in tables should have been mentioned in the text and the reason for their inclusion discussed.

As part of the review process, you may be asked to submit additional documentation if procedures are not sufficiently clear; the review process works most efficiently if such information is given in the initial submission. If you advise readers that additional information is available, you should submit printed copies of that information with the manuscript. If the amount of this supplementary information is extensive, please inquire about alternate procedures.

The APSR uses a double-blind review process. You should follow the guidelines for preparing anonymous copies in the Specific Procedures section below.

Manuscripts that are largely or entirely critiques or commentaries on previously published APSR articles will be reviewed using the same general procedures as for other manuscripts, with one exception. In addition to the usual number of reviewers, such manuscripts will also be sent to the scholar(s) whose work is being criticized, in the same anonymous form that they are sent to reviewers. Comments from the original author(s) to the Editor will be invited as a supplement to the advice of reviewers. This notice to the original author(s) is intended (1) to encourage review of the details of analyses or research procedures that might escape the notice of disinterested reviewers; (2) to enable prompt publication of critiques by supplying criticized authors with early notice of their existence and, therefore, more adequate time to reply; and (3) as a courtesy to criticized authors. If you submit such a manuscript, you should therefore send as many additional copies of their manuscripts as will be required for this purpose.

Manuscripts being submitted for publication should be sent to Lee Sigelman, Editor, American Political Science Review, Department of Political Science, The George Washington University, Washington, DC 20052. Correspondence concerning manuscripts under review may be sent to the same address or e-mailed to apsr@gwu.edu.

\section{Manuscript Formatting}

Manuscripts should not be longer than 45 pages including text, all tables and figures, notes, references, and appendices. This page size guideline is based on the U.S. standard $8.5 \times 11$-inch paper; if you are submitting a manuscript printed on longer paper, you must adjust accordingly. The font size must be at least 11 points for all parts of the paper, including notes and references. The entire paper, including notes and references, must be double-spaced, with the sole exception of tables for which double-spacing would require a second page otherwise not needed. All pages should be numbered in one sequence, and text should be formatted using a normal single column no wider than 6.5 inches, as is typical for manuscripts (rather than the double-column format of the published version of the APSR), and printed on one side of the page only. Include an abstract of no more than 150 words. The $A P S R$ style of embedded citations should be used, and there must be a separate list of references at the end of the manuscript. Do not use notes for simple citations. These specifications are designed to make it easier for reviewers to read and evaluate papers. Papers not adhering to these guidelines are subject to being rejected without review.

For submission and review purposes, you may place footnotes at the bottom of the pages instead of using endnotes, and you may locate tables and figures (on separate pages and only one to a page) approximately where they fall in the text. However, manuscripts accepted for publication must be submitted with endnotes, and with tables and figures on separate pages at the back of the manuscript with standard indications of text placement, e.g., [Table 3 about here]. In deciding how to format your initial submission, please consider the necessity of making these changes if your paper is accepted. If your paper is accepted for publication, you will also be required to submit camera-ready copy of graphs or other types of figures. Instructions will be provided.

For specific formatting style of citations and references, please refer to articles in the most recent issue of the APSR. For unusual style or formatting issues, you should consult the latest edition of The Chicago Manual of Style. For review purposes, citations and references need not be in specific APSR format, although some generally accepted format should be used, and all citation and reference information should be provided.

\section{Specific Procedures}

Please follow these specific procedures for submission:

1. You are invited to submit a list of scholars who would be appropriate reviewers of your manuscript. The Editor will refer to this list in selecting reviewers, though there obviously can be no guarantee that those you suggest will actually be chosen. Do not list anyone who has already commented on your paper or an earlier version of it, or any of your current or recent collaborators, institutional colleagues, mentors, students, or close friends.

2. Submit five copies of manuscripts and a diskette containing a pdf file of the anonymous version of the manuscript. If you cannot save the manuscript as a pdf, just send in the diskette with the word-processed version. Please ensure that the paper and diskette versions you submit are identical; the diskette version should be of the anonymous copy (see below). Please review all pages of all copies to make sure that all copies contain all tables, figures, appendices, and bibliography mentioned in the manuscript and that all pages are legible. Label the diskette 
clearly with the (first) author's name and the title of the manuscript (in abridged form if need be), and identify the word processing program and operating system.

3. To comply with the APSR's procedure of double-blind peer reviews, only one of the five copies submitted should be fully identified as to authorship and four should be in anonymous format.

4. For anonymous copies, if it is important to the development of the paper that your previous publications be cited, please do this in a way that does not make the authorship of the submitted paper obvious. This is usually most easily accomplished by referring to yourself in the third person and including normal references to the work cited in the list of references. In no circumstances should your prior publications be included in the bibliography in their normal alphabetical location but with your name deleted. Assuming that text references to your previous work are in the third person, you should include full citations as usual in the bibliography. Please discuss the use of other procedures to render manuscripts anonymous with the Editor prior to submission. You should not thank colleagues in notes or elsewhere in the body of the paper or mention institution names, web page addresses, or other potentially identifying information. All acknowledgments must appear on the title page of the identified copy only. Manuscripts that are judged not anonymous will not be reviewed.

5. The first page of the four anonymous copies should contain only the title and an abstract of no more than 150 words. The first page of the identified copy should contain (a) the name, academic rank, institutional affiliation, and contact information (mailing address, telephone, fax, e-mail address) for all authors; (b) in the case of multiple authors, an indication of the author who will receive correspondence; (c) any relevant citations to your previous work that have been omitted from the anonymous copies; and (d) acknowledgments, including the names of anyone who has provided comments on the manuscript. If the identified copy contains any unique references or is worded differently in any way, please mark this copy with "Contains author citations" at the top of the first page.

No copies of submitted manuscripts can be returned.

\section{ELECTRONIC ACCESS TO THE APSR}

Back issues of the APSR are available in several electronic formats and through several vendors. Except for the last three years (as an annually "moving wall"), back issues of the APSR beginning with Volume 1, Number 1 (November 1906), are available on-line through JSTOR (http://wwwjstor.org/). At present,
JSTOR's complete journal collection is available only via institutional subscription, e.g., through many college and university libraries. For APSA members who do not have access to an institutional subscription to JSTOR, individual subscriptions to its $A P S R$ content are available. Please contact Member Services at APSA for further information, including annual subscription fees.

Individual members of the American Political Science Association can access recent issues of the APSR and $P S$ through the APSA website (www.apsanet.org) with their username and password. Individual nonmember access to the online edition will also be available, but only through institutions that hold either a print-plus-electronic subscription or an electronic-only subscription, provided the institution has registered and activated its online subscription.

Full text access to current issues of both the APSR and $P S$ is also available on-line by library subscription from a number of database vendors. Currently, these include University Microfilms Inc. (UMI) (via its CDROMs General Periodicals Online and Social Science Index and the on-line database ProQuest Direct), Online Computer Library Center (OCLC) (through its on-line database First Search as well as on CD-ROMs and magnetic tape), and the Information Access Company (IAC) (through its products Expanded Academic Index, InfoTrac, and several on-line services [see below]). Others may be added from time to time.

The APSR is also available on databases through six online services: Datastar (Datastar), Business Library (Dow Jones), Cognito (IAC), Encarta Online Library (IAC), IAC Business (Dialog), and Newsearch (Dialog).

The editorial office of the APSR is not involved in the subscription process to either JSTOR for back issues or the other vendors for current issues. Please contact APSA, your reference librarian, or the database vendor for further information about availability.

\section{BOOK REVIEWS}

The APSR no longer contains book reviews. As of 2003, book reviews have moved to Perspectives on Politics. All books for review should be sent directly to the Perspectives on Politics Book Review Editors, Susan Bickford and Greg McAvoy. The address is Susan Bickford and Gregory McAvoy, Perspectives on Politics Book Review Editors, Department of Political Science, University of North Carolina at Chapel Hill, CB No. 3265, Chapel Hill, NC 27599-3265. E-mail: bookreviews@unc.edu.

If you are the author of a book you wish to be considered for review, please ask your publisher to send a copy to the Perspectives on Politics Book Review Editors per the mailing instructions above. If you are interested in reviewing books for Perspectives on Politics, please send your vita to the Book Review Editors; you should not ask to review a specific book. 


\section{OTHER CORRESPONDENCE}

The American Political Science Association's address, telephone, and fax are 1527 New Hampshire Avenue, N.W., Washington, D.C. 20036, (202) 483-2512 (voice), and (202) 483-2657 (fax). E-mail: apsa@apsanet.org. Please direct correspondence as follows.

Information, including news and notes, for $P S$ :

Dr. Robert J-P. Hauck, Editor, $P S$

E-mail: rhauck@apsanet.org

Circulation and subscription correspondence (domestic claims for nonreceipt of issues must be made within four months of the month of publication; overseas claims, within eight months):

Elizabeth Weaver Engel,

Director of Member Services

E-mail: membership@apsanet.org

Reprint permissions:

E-mail: reprints@apsanet.org

Advertising information and rates:

Advertising Coordinator,

Cambridge University Press

E-mail: journals_advertising@cup.org

\section{EXPEDITING REQUESTS FOR COPYING APSR AND PS ARTICLES FOR CLASS USE AND OTHER PURPOSES}

\section{Class Use}

The Comprehensive Publisher Photocopy Agreement between APSA and the Copyright Clearance Center (CCC) permits bookstores and copy centers to receive expedited clearance to copy articles from the $A P S R$ and $P S$ in compliance with the Association's policies and applicable fees. The general fee for articles is 75 cents per copy. However, current Association policy levies no fee for the first 10 copies of a printed artide, whether in course packs or on reserve. Smaller classes that rely heavily on articles (i.e., upper-level undergraduate and graduate classes) can take advantage of this provision, and faculty ordering 10 or fewer course packs should bring it to the attention of course pack providers. APSA policy also permits free use of the electronic library reserve, with no limit on the number of students who can access the electronic reserve. Both large and small classes that rely on these articles can take advantage of this provision. The CCC's address, telephone, and fax are 222 Rosewood Drive, Danvers, MA 01923, (978) 750-8400 (voice), and (978) 750-4474 (fax). This agreement pertains only to the reproduction and distribution of APSA materials as hard copies (e.g., photocopies, microfilm, and microfiche).

The Association of American Publishers (AAP) has created a standardized form for college faculty to submit to a copy center or bookstore to request copyrighted material for course packs. The form is available through the $\mathrm{CCC}$, which will handle copyright permissions.

APSA also has a separate agreement pertaining to CCC's Academic E-Reserve Service. This agreement allows electronic access for students and instructors of a designated class at a designated institution for a specified article or set of articles in electronic format. Access is by password for the duration of a class.

Please contact your librarian, the CCC, or the APSA Reprints Department for further information.

\section{APSR Authors}

If you are the author of an APSR article, you may use your article in course packs or other printed materials without payment of royalty fees and you may post it at personal or institutional web sites as long as the APSA copyright notice is included.

\section{Other Uses of APSA-Copyrighted Materials}

For any further copyright issues, please contact the APSA Reprints Department.

\section{INDEXING}

Articles appearing in the APSR before June 1953 were indexed in The Reader's Guide to Periodical Literature. Current issues are indexed in ABC Pol Sci; America, History and Life 1954-; Book Review Index; Current Contents: Social and Behavioral Sciences; EconLit; Energy Information Abstracts; Environmental Abstracts; Historical Abstracts; Index of Economic Articles; Information Service Bulletin; International Index; International Political Science Abstracts; the Journal of Economic Literature; Periodical Abstracts; Public Affairs; Public Affairs Information Service International Recently Published Articles; Reference Sources; Social Sciences and Humanities Index; Social Sciences Index; Social Work Research and Abstracts; and Writings on American History. Some of these sources may be available in electronic form through local public or educational libraries. Microfilm of the $A P S R$, beginning with Volume 1, and the index of the APSR through 1969 are available through University Microfilms Inc., 300 North Zeeb Road, Ann Arbor, MI 48106 (www.umi.com). The Cumulative Index to the American Political Science Review, Volumes 63 to 89: 1969-95, is available through the APSA. 